\title{
STRUCTURAL CONFIGURATIONS OF THIN DRIED POLYANILINE FILMS ON GOLD(111) FROM SCANNING TUNNELING MICROSCOPY
}

\author{
M. E. Vela $\uparrow$ J. L. Zubimendi, $\dagger$ P. Ocón, $\ddagger$ P. IIerrasti, $\ddagger$ R. C. Salvarezza $†$ L. \\ VÁZQUEZ§ and A. J. ARVIA*, $\dagger$ \\ $\dagger$ Instituto de Investigaciones Fisicoquimicas Teóricas y Aplicadas (INIFTA), Sucursal 4, Casilla de \\ Correo 16, 1900 La Plata, Argentina \\ $\ddagger$ Departamento de Química Física Aplicada C-1I, Universidad Autónoma de Madrid (UAM), 28049. \\ Madrid (Spain) \\ § Instituto de Ciencia de Materiales, CSIC, Dpto. Fisica Aplicada, C-XII, Universidad Autónoma de \\ Madrid (UAM), 28049, Madrid (Spain)
}

\section{(Received 8 September 1995)}

\begin{abstract}
The early stages of growth of polyaniline films electrodeposited on Au were studied by conventional electrochemical techniques, X-ray diffraction and ex situ scanning tunneling microscopy (STM). From high resolution STM imaging it appears that the first step of polyaniline formation involves the adsorption of aniline monomers on Au(111) terraces leading to domains with hexagonal arrays involving a phenyl-phenyl distance in the range $0.70 \mathrm{~nm} \leqslant d \leqslant 1.0 \mathrm{~nm}$. The second step corresponds to the initiation of the polymer growth yielding typically $10 \times 10 \mathrm{~nm}^{2}$ crystalline domains consisting of either $0.45 \times 0.6 \mathrm{~nm}^{2}$ rectangular arrays or $0.75 \times 0.45 \mathrm{~nm}^{2}$ arrays forming $120^{\circ}$ angles. The crystalline domains coexist with highly disordered polymer domains. At advanced stages of growth, the formation of polymer fibers $2 \mathrm{~nm}$ in average width takes place leading to a full substrate coverage by a polymer deposit with an irregular surface. Copyright $\mathrm{C}$ ' 1996 Elsevier Science Ltd
\end{abstract}

Key words: conducting polymers, thin polyaniline films. STM imaging, early stage structures.

\section{INTRODUCTION}

Conducting polymers constitute a group of new materials of great interest due to their specific properties, simple preparation, high stability in different environments and possible application to electrochemical energy conversion, electrocatalysis and electro-optical displays[1]. Among the different conducting polymers available at present, high quality polyaniline and other related polymer coatings $[1,2]$ can be produced by electrochemical methods. The growth kinetics, the oxidized and reduced states, the conducting properties of polyaniline films, as well as the effect of dopants such as anions on these properties, have been extensively considered[1]. In contrast, little is known about the polymer structure itself at the nanometer level, particularly at the early stages of growth. There are still some unresolved questions related to the presence of amorphous and crystalline domains in the early and advanced stages of polymer film formation, and the possible participation of adsorbed species as precursors of the electropolymerization reaction[3].

Scanning tunneling microscopy (STM) and atomic force microscopy (AFM) of polyaniline and related polymer films $[4,5]$ at advanced stages of growth have shown that the surface structure of these films

* Author to whom correspondence should be addressed. can be described as a fractal formed by the agglomeration of rounded elements $20 \mathrm{~nm}$ in average size[5]. However, the resolution of polymer chains and monomer units on these rounded elements has not yet been achieved[4, 5]. Recent STM data[6, 7] have revealed that at the early stages of polyaniline growth ordered domains with a chain-chain distance of about $0.6 \mathrm{~nm}$, and a phenyl-phenyl distance close to $1 \mathrm{~nm}$ are formed[5]. Unfortunately, these results were obtained from films grown on either an unknown substrate or highly oriented pyrolytic graphite (HOPG). For the latter, it is well known that a number of STM imaging artifacts may be produced by the substrate itself [8].

This work reports the STM imaging of polyaniline thin films electrochemically grown on vapor deposited gold substrates. The high stability of polyaniline films in air at room temperature[6] makes it possible to use the ex situ-STM technique for this study.

High resolution STM imaging of deposits formed at the early stages of polyaniline growth on vapor deposited gold shows that polymer film formation is preceded by the appearance of ordered domains of adsorbed aniline species (monomers) forming hexagonal arrays on the $\mathrm{Au}(111)$ terraces of the substrate. Adsorbed aniline species would act as precursors of polyaniline formation. Likewise. polymer growth is accompanied by the formation of different ordered surface structures involving 10-20 monomer units which coexist with other domains 
where monomers are randomly located. At advanced stages of growth polymer chains agglomerate to form fibers, and finally bundles which lead to a strongly disordered polymer surface.

\section{EXPERIMENTAL}

Polyaniline films were formed on a working electrode consisting of a vapor deposited gold film on a glass plate at $673^{\circ} \mathrm{K}[9]$. This type of gold film exhibited large flat (111) terraces which were characterized by STM imaging and X-ray diffractometry. The structure of the polymer electrodeposited on this substrate could be discriminated from that of underlying gold and adequately determined at the different stages of growth.

The working electrode, the counterelectrode made from a Pt plate, and the $\mathrm{Hg} / \mathrm{Hg}_{2} \mathrm{SO}_{4} / \mathrm{K}_{2} \mathrm{SO}_{4}$ (sat) reference electrode were assembled in a conventional glass-made electrochemical cell containing nitrogen saturated aqueous $0.5 \mathrm{M} \mathrm{H} \mathrm{H}_{2} \mathrm{SO}_{4}+0.1 \mathrm{M}$ aniline solution. Potentials in the text are referred to the SHE scale. Solutions were prepared from $p a$. reagents and Milli- $Q^{*}$ water. Runs were performed at $298^{\circ} \mathrm{K}$

Polymer films were grown by repetitive triangular potential scanning between a low switching potential, $E_{1}=0 \mathrm{~V}$, and an upper switching potential, $E_{\mathrm{u}}=0.97 \mathrm{~V}$, at the potential sweep rate $v=0.05 \mathrm{Vs}^{-1}$. The polyaniline covered Au electrodes were removed from the cell at $E_{\mathrm{r}}=0.65 \mathrm{~V}$, carefully washed with thrice distilled water and dried under purified nitrogen. Immediately after drying, the polyaniline coated Au electrodes were imaged using a McAllister STM operating in air. Occasionally, a Nanoscope III equipment was used. Scanning tunneling microscopes were calibrated by imaging the HOPG surface. Tips were made by cutting $0.5 \mathrm{~mm}$-dia Pt-Ir wires. STM images were obtained in the topographic mode using a bias voltage $V_{1}$ in the range $20-100 \mathrm{mV}$ and a tunneling current $i_{1}$ in the range 1-20 nA. STM data were acquired at a fully automated workstation and stored as digitized images with either $200 \times 200$ or $256 \times 256$ pixels. STM imaging at different stages of polyaniline formation was made.

$\mathrm{X}$-ray diffractometry was used as a complementary technique for the characterization of both the gold substrate and polymer films.

\section{RESULTS AND INTERPRETATION}

\section{Voltammetric aniline electropolymerization data}

Polyaniline film formation can be followed by cycling voltammetry starting from $E_{1}=0 \mathrm{~V}$ up to $E_{u}=0.97 \mathrm{~V}$ at $v=0.05 \mathrm{~V} \mathrm{~s}^{-1}$ (Fig. 1a). The 7th, 9th and 12th voltammetric scans run from $E_{1}$ upwards exhibit a well-defined anodic current peak $A_{1}$ at about $c a .0 .38 \mathrm{~V}$, followed by an anodic current $\left(A_{11}\right)$ increasing slightly as the potential extends from about $0.4 \mathrm{~V}$ to $0.8 \mathrm{~V}$. Subsequently, a sharp anodic current increase $\left(A_{I I I}\right)$ with potential is observed. The reverse potential scan run from $E_{\mathrm{u}}=0.97 \mathrm{~V}$ downwards shows first a current plateau $\left(\mathrm{C}_{\mathrm{II}}\right)$ extending up
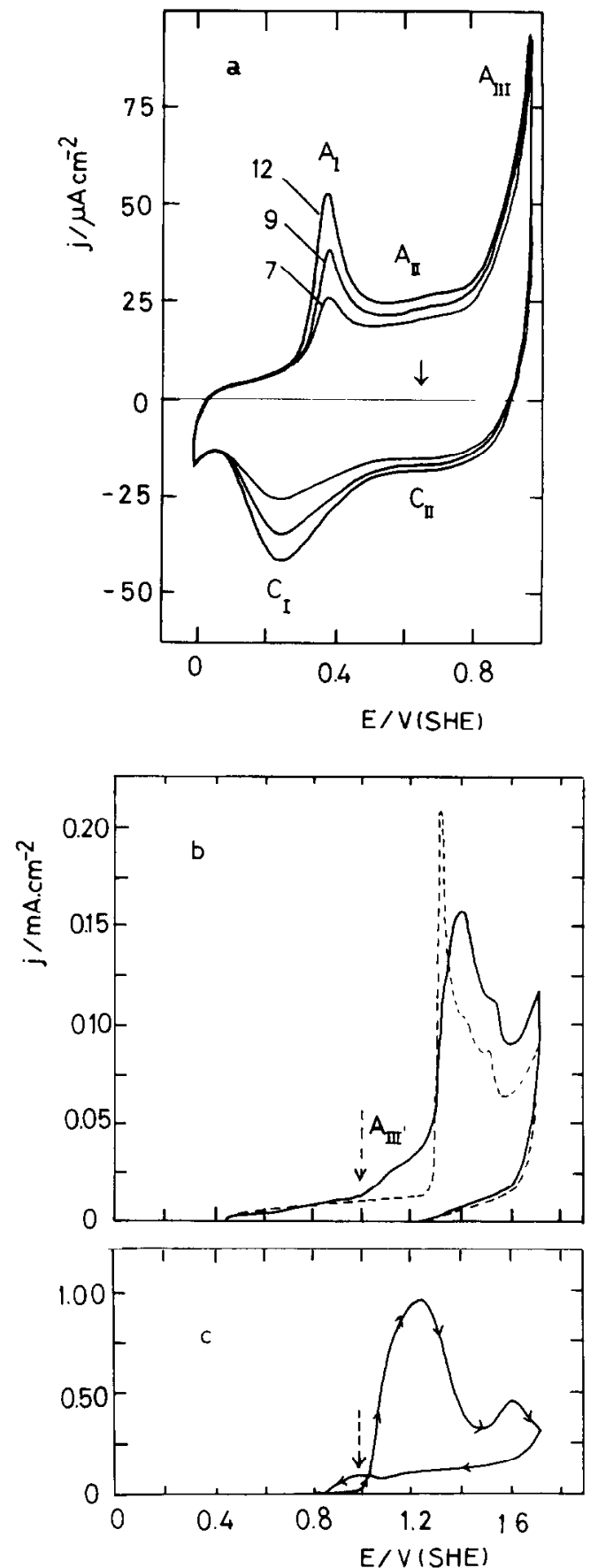

Fig. 1. (a) Voltammograms (7th, 9th, 12th scan) for aniline electropolymerization on vapor deposited $\mathrm{Au}$. $0.5 \mathrm{M}$ $\mathrm{H}_{2} \mathrm{SO}_{4}+0.1 \mathrm{M}$ aniline, $v=0.05 \mathrm{~V} \mathrm{~s}^{-1}$. (b) ( $(-)$ currentpotential profile recorded in $0.5 \mathrm{M} \mathrm{H}_{2} \mathrm{SO}_{4}$ at $v=0.05 \mathrm{~V} \mathrm{~s}^{-1}$ after aniline adsorption in $0.5 \mathrm{M} \mathrm{H}_{2} \mathrm{SO}_{4}+0.1 \mathrm{M}$ aniline at $E_{\mathrm{d}}=0.45 \mathrm{~V}$ for $t_{\mathrm{d}}=15 \mathrm{~min}$; (---) similar experiment made in $0.5 \mathrm{M} \mathrm{H}_{2} \mathrm{SO}_{4}$ at $E_{\mathrm{d}}=0.45 \mathrm{~V}$ for $t_{\mathrm{d}}=15 \mathrm{~min}$. (c) First current potential profile at $v=0.05 \mathrm{~V} \mathrm{~s}^{-1}$ for a vapor deposited $\mathrm{Au}$ electrode in $0.5 \mathrm{M} \mathrm{H}_{2} \mathrm{SO}_{4}+0.1 \mathrm{M}$ aniline.

to $0.5 \mathrm{~V}$ followed by a broad cathodic current peak $\left(C_{1}\right)$ at $c a .0 .25 \mathrm{~V}$. The height of the conjugated peaks $A_{I}$ and $C_{I}$, as well as currents $A_{I I}$ and $C_{I I}$, increases with $\mathrm{N}$, the number of voltammetric scans (Fig. 1a). Peaks $A_{1}$ and $C_{1}$ correspond to the redox reactions 
involving the electroformation and electroreduction of the leucoemeraldine form of the polymer, whereas peak $A_{I I I}$ corresponds to the formation of polyemeraldine $[1,2]$. The absence of current peaks in the potential range of current $A_{I I}$ and $C_{I I}$ indicates that there is an insignificant contribution of degradation products of the benzoquinonic type which would be formed at $E_{u}>1 \mathrm{~V}$. The arrow in the voltammogram (Fig. la) indicates the potential at which the electrode was removed from the cell for STM imaging.

\section{Electrochemical data related to the early stages of aniline electropolymerization}

The value of $\langle\delta\rangle$, the average thickncss of the clectrode surface coating, was estimated from Faraday law[10].

$$
\langle\delta\rangle=q V_{\mathbf{m}} / z F
$$

where $q$ is the overall anodic charge density derived from voltammetry, $V_{\mathrm{m}}=91.9 \mathrm{~cm}^{3} \mathrm{~mol}^{-1}$ is the aniline molar volume, $z=3$ is the number of electron entering reaction (1)[10], and $F$ is Faraday consiant. Values of $q$ were in the range $0.1 \mathrm{mC} \mathrm{cm}^{-2} \leqslant q \leqslant 1.2 \mathrm{mC} \mathrm{cm}^{-2}$. leading to values of $\delta$ in the range $0.3 \mathrm{~nm} \leqslant \delta \leqslant 4 \mathrm{~nm}$. These figures indicate that only very thin electropolymer films have been considered in this work, with the main purpose of studying the surface structure of those films formed at the very early stages of the aniline electropolymerization reaction.

Firstly, the possible participation of adsorbed aniline monomers in electropolymerization was investigated. For this purpose, a polycrystalline $\mathrm{Au}$ electrode was immersed in aqueous $0.5 \mathrm{M} \mathrm{H}_{2} \mathrm{SO}_{4}$ $+0.1 \mathrm{M}$ aniline solution and held at $E_{\mathrm{d}}=0.45 \mathrm{~V}$, for $t_{\mathrm{d}}=15 \mathrm{~min}$. This potential lies in the double layer potential range of $\mathrm{Au}$ in acid, and therefore, no aniline electro-oxidation takes place there. Then, the Au electrode was removed from the cell by holding the potential at $E_{\mathrm{d}}=0.45 \mathrm{~V}$, rinsed with nitrogen saturated Milli- $\mathrm{Q}^{*}$ water, and placed into another cell containing nitrogen saturated aqueous $0.5 \mathrm{M}$ $\mathrm{H}_{2} \mathrm{SO}_{4}$. Subsequently, the potential was scanned from $E_{\mathrm{d}}$ upwards at $v=0.05 \mathrm{~V} \mathrm{~s}^{-1}$ to electro-oxidize those aniline monomers remaining on $\mathrm{Au}$, and to observe those current peaks related to the formation and electroreduction of the O-containing monolayer on $\mathrm{Au}$ (11). The current/potential profiles resulting from these runs (Fig. 1b, solid line) exhibit an anodic current peak $A_{\text {III }}^{\prime}$ at $1.1 \mathrm{~V}$. This peak is absent from those runs made in aqueous $0.5 \mathrm{M} \mathrm{H}_{2} \mathrm{SO}_{4}$ after holding the potential at $E_{\mathrm{d}}-0.45 \mathrm{~V}$ for $t_{\mathrm{d}}-15 \mathrm{~m}$ (Fig. $1 \mathrm{~b}$, dashed line). In this case, the anodic potentiodynamic scan reproduces well-established current/ potential profiles of polycrystalline $\mathrm{Au}$ in the acid solution[11].

The threshold potential (Fig. 1b, dashed arrow) of peak $\left(A_{\text {III }}^{\prime}\right)$ coincides with the potential at which the voltammetric electro-oxidation of aniline monomer in aqueous $0.5 \mathrm{M} \mathrm{H}_{2} \mathrm{SO}_{4}+0.1 \mathrm{M}$ aniline solution begins to be observed in the first anodic scan (Fig. 1c). These results are similar to those which have been reported for the irreversible adsorption of aniline cationic monomers on $\mathrm{Pt}(111)$ in contact with aniline in $0.5 \mathrm{M} \mathrm{H}_{2} \mathrm{SO}_{4}$ [12]. In fact, for aqueous $0.5 \mathrm{M} \mathrm{H}_{2} \mathrm{SO}_{4}$ the cationic form of aniline prevails at the electrode/solution interface. Therefore, it appears that adsorbed aniline species are also involved to some extent in the electropolymerization of aniline on Au.

\section{X-ray diffraction data}

The X-ray diffractograms of the vapor deposited gold substrate (Fig. 2a) show a large diffraction peak at the interplanar distance, $d=0.2354 \mathrm{~nm}$, which indicates that the $A u(111)$ crystallographic structure dominates the Au topography. The X-ray diffractogram of the Au substrate smears out when it is progressively covered by the polymer layer. Thus, for a polymer film equivalent to $q=0.35 \mathrm{mC} \mathrm{cm}^{-2}$ (Fig. $2 b)$, the X-ray diffractogram shows two sharp peaks at interplanar spacings, $d_{1}=0.912 \mathrm{~nm}$ and $d_{2}=$ $0.504 \mathrm{~nm}$. The sharpness of these peaks suggests that the polyaniline film exhibits a certain degree of crystallinity, at least in the early stages of growth.

\section{Structural interpretation from STM imaging data.}

STM images of the vapor deposited gold substrate show atomically smooth terraces (Fig. 3a) 100$500 \mathrm{~nm}$ in size and monoatomic steps (Fig. 3b). The angles formed by crossing steps are consistent with the $\mathrm{Au}(111)$ structure, as concluded from X-ray diffraction data.

On the other hand, STM images resulting from the Au substrate covered by a polymer film show different features depending on the amount of the deposited polymer. Thus, STM images on a substrate covered by a polymer film equivalent to $q=0.3 \mathrm{mC} \mathrm{cm}^{-2}$, show both ordered and disordered nanostructures (Fig. 4). On the left hand side (upper part) of this image, an ordered array of rings coexists with fibers $2 \mathrm{~nm}$ in width formed by rounded elements $0.5 \mathrm{~nm}$ in size. The corrugation of the fibers seen on the right hand side (lower part) of the image is close to $0.25 \mathrm{~nm}$, and the average closest fiber-tofiber separation is about $2 \mathrm{~nm}$. The STM image also shows that the fibers are placed on the ordered ringlike structure.

The STM images of ordered arrays of rings reveal parallel rows intersecting at $60^{\circ}$ angles suggesting a probable influence of the $A u(111)$ substrate on the polymer film arrangement (Fig. 5a). The rings form a hexagonal lattice with a ring-ring distance $d=0.7 \mathrm{~nm}$ (Fig. 5b). In other regions hexagonal arrangements formed by bright spots (Fig. 5c) with a spot-to-spot distance, $d=0.7 \mathrm{~nm}$ (Fig. $5 \mathrm{~d}$ ), can be also observed. Both, the ring and spot hexagonal arrays involve the same corrugation, $d_{z} \cong 0.1 \mathrm{~nm}$. Neither the value $d=0.7 \mathrm{~nm}$ nor the value $d_{\mathrm{z}}=$ $0.1 \mathrm{~nm}$ can be assigned to the $\mathrm{Au}(111)$ substrate, as the Au-Au atom distance is $d_{\mathrm{Au}-\mathrm{Au}}=0.29 \mathrm{~nm}$, and the corrugation is $d_{2 A u}=0.010 .03 \mathrm{~nm}[13,14]$. On the other hand, the "spot" and "ring" images are similar to those reported for benzene adsorption on different sites of transition metals[15, 16]. In principle, the STM images depicted in Fig. 5 can be interpreted as images of polymer chains in which phenyl groups are resolved, although it should be 


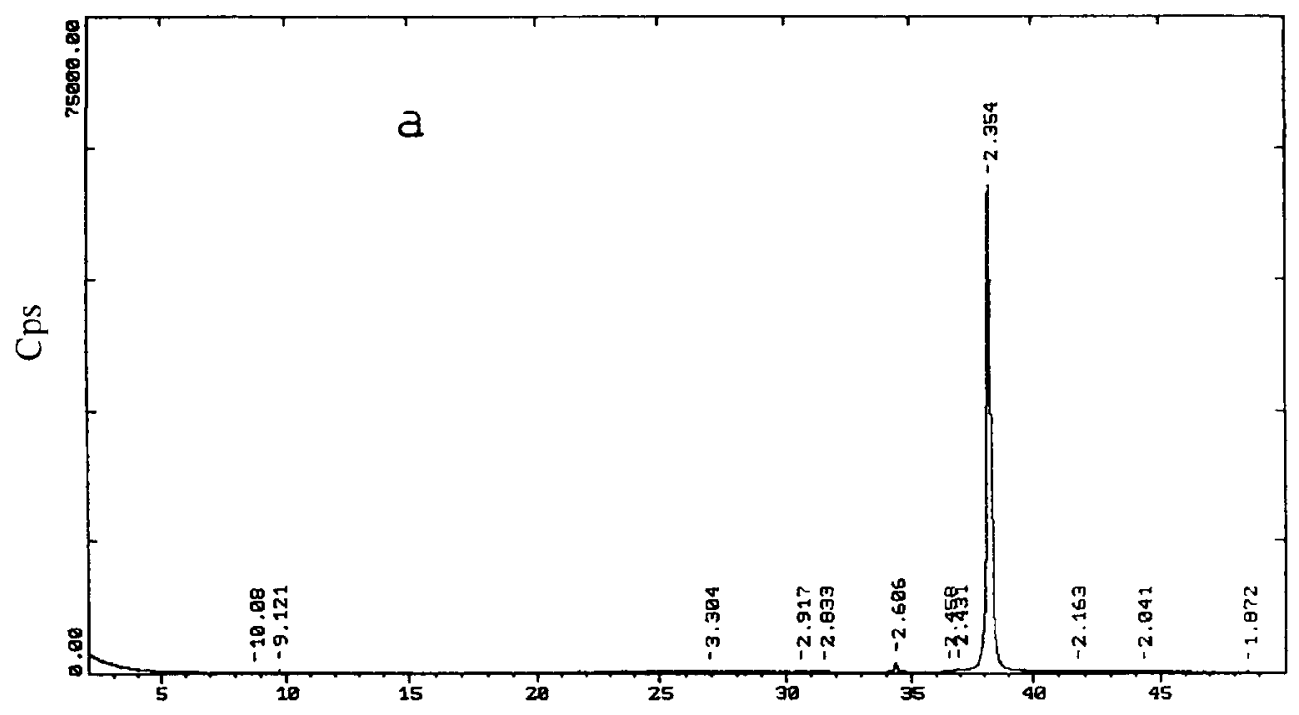

$2 \theta$

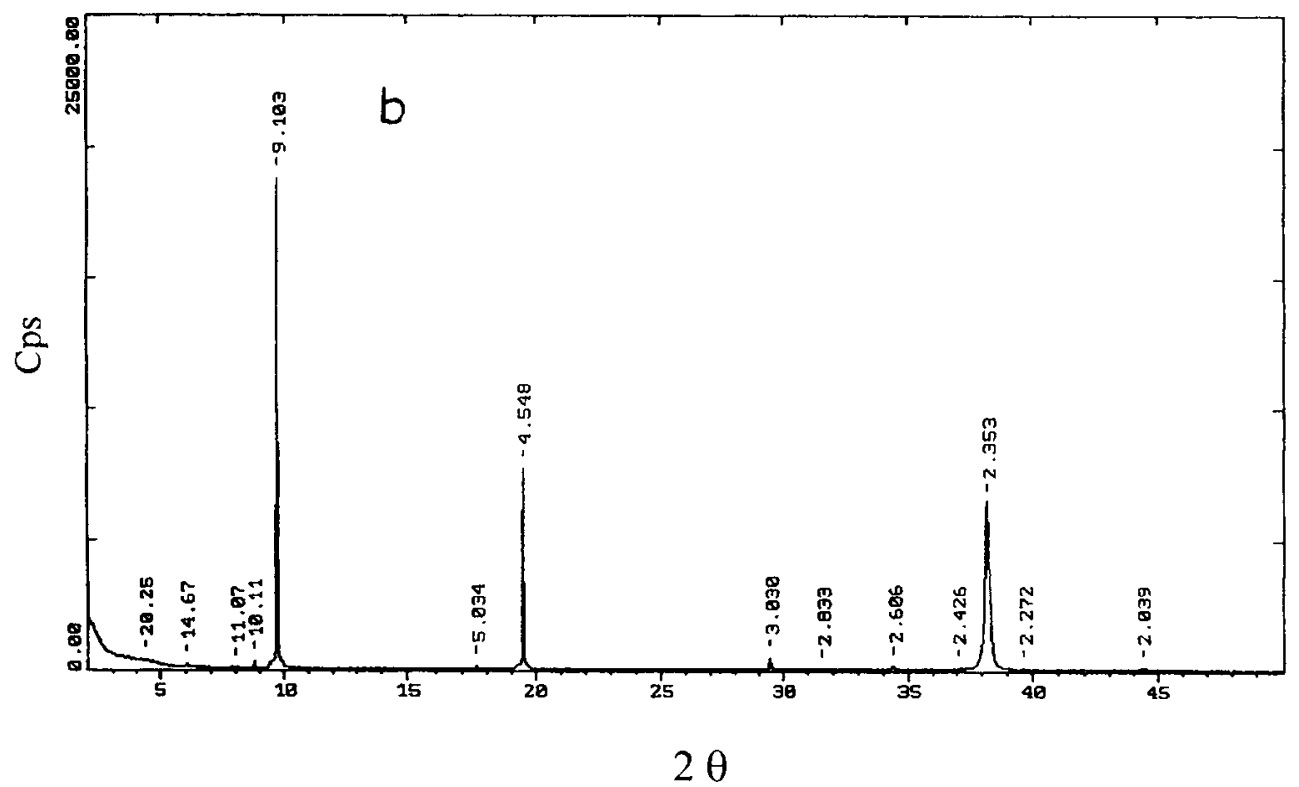

Fig. 2. X-ray diffractrograms of the vapor deposited gold substrate (a) and the vapor deposited gold substrate covered by a polyaniline layer (b) equivalent to $q=0.35 \mathrm{mC} \mathrm{cm}^{-2}$.

noted that while $d_{\mathrm{z}}$ is close to the value expected for phenyl rings[15], the value $d=0.7 \mathrm{~nm}$ is beyond any predictable phenyl-phenyl ring distance in the polymer chain[6]. However, the value $d=0.7 \mathrm{~nm}$ would correspond to a hexagonal array of aniline monomer adsorbates alternating on Au(111) terraces. The presence of adsorbed aniline monomers at the initial stages of aniline electropolymerization is consistent with electrochemical data (Fig. 1b,c). Considering that the values of $E_{\mathrm{d}}=0.45 \mathrm{~V}$ and $E_{\mathrm{r}}=$ $0.65 \mathrm{~V}$ used in this work are positive with respect to the potential of zero charge of $\mathrm{Au}(111)$ in aqueous solutions $\left(E_{\mathrm{z}} \cong 0.05 \mathrm{~V}\right.$ at $\left.298^{\circ} \mathrm{K}\right)[14]$, it is most likely that the aniline adsorbate-gold interaction involves predominatly $\pi$-electrons of phenyl ring and $d$ metal orbitals. Accordingly, adsorbed aniline species would lie parallel to the gold surface, as concluded from high resolution STM images. This interpretation agrees with that already advanced for the adsorption of aniline on both polycrystalline $A u[17]$ and $\operatorname{Pt}(111)[12]$ electrodes.

Further hexagonal arrays with $d \cong 0.5$ and $d \cong 1 \mathrm{~nm}$ (Figs. 6a and 8 ) can be also observed. However, these distances are also expected for phenyl groups in the adjacent polyaniline chains[6]. Therefore, it is difficult to decide whether such structures might result from adsorbed monomers or polyaniline chains forming hexagonal arrays.

STM images of those regions surrounding polyaniline fiber-like structure domains (Fig. 6a) also show 


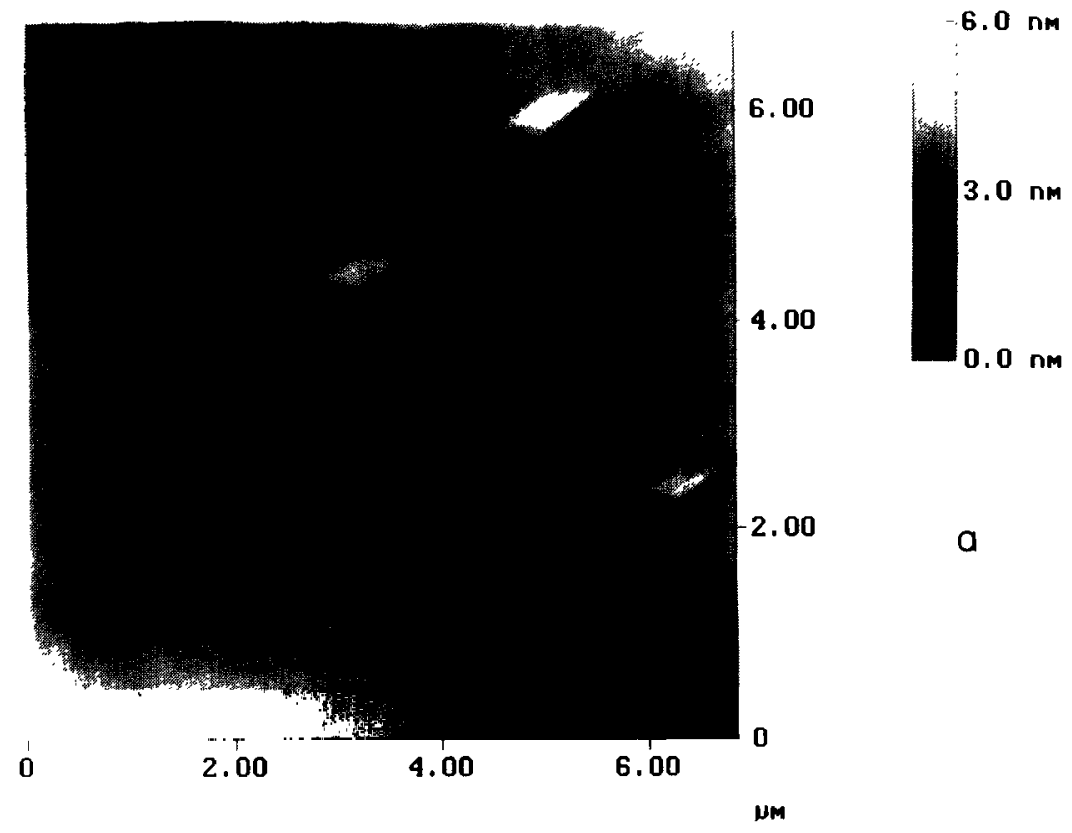

b
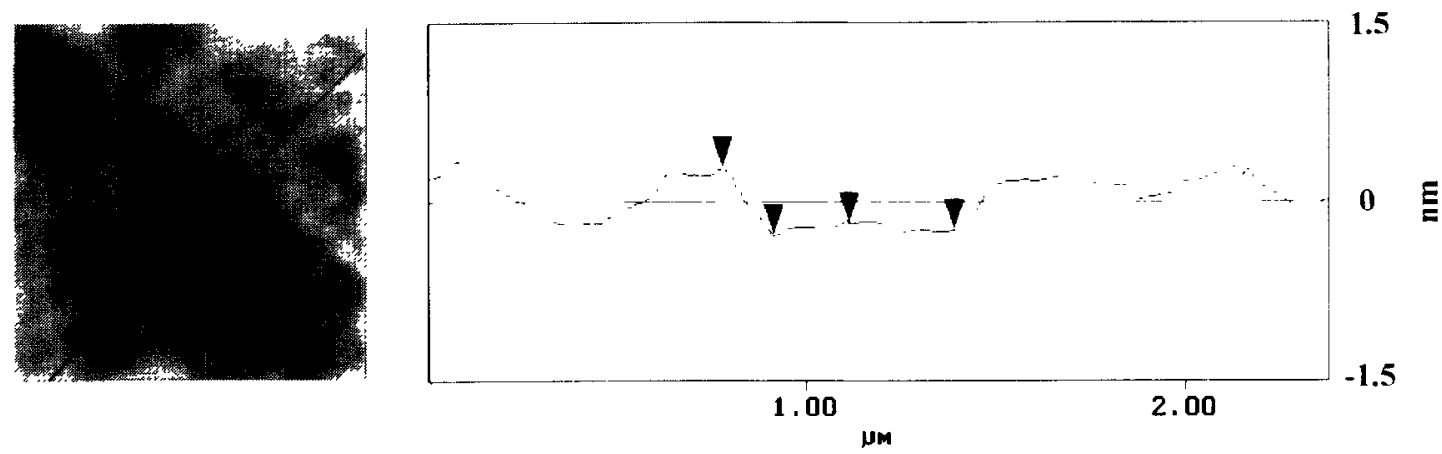

Fig. 3. (a) $6.85 \times 6.85 \mathrm{~nm}^{2}$ STM image of the gold substrate. (b) Cross-section showing terrace size and step height.

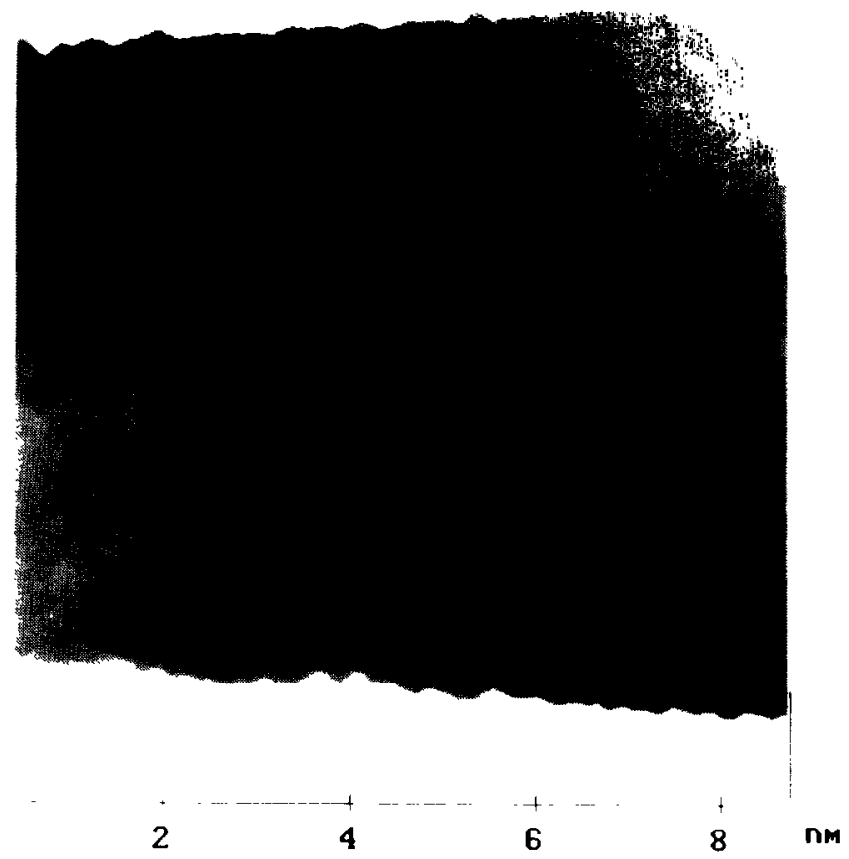

Fig. $4.8 .7 \times 8.7 \mathrm{~nm}^{2}$ STM image of a polyaniline covered $\left(q=0.3 \mathrm{mCcm}{ }^{-2}\right)$ gold substrate. Ordered domains (upper part left-hand side) and disordered fibers formed by rounded elements are observed. 
a

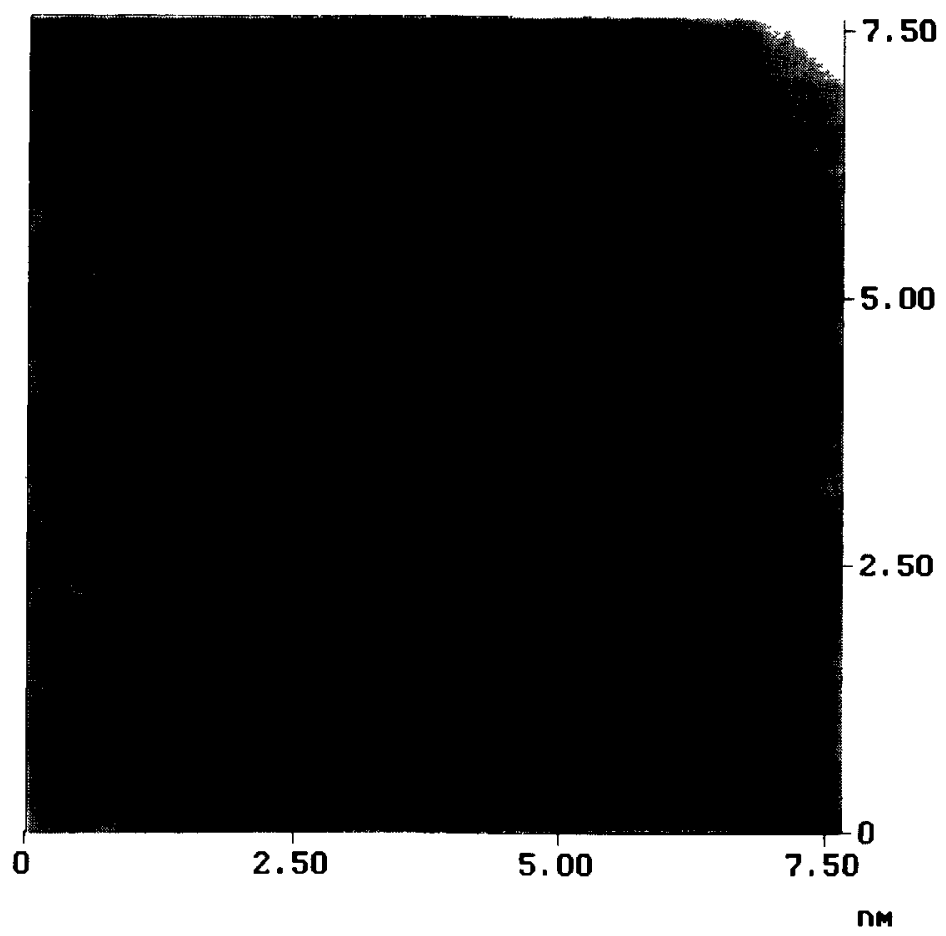

b

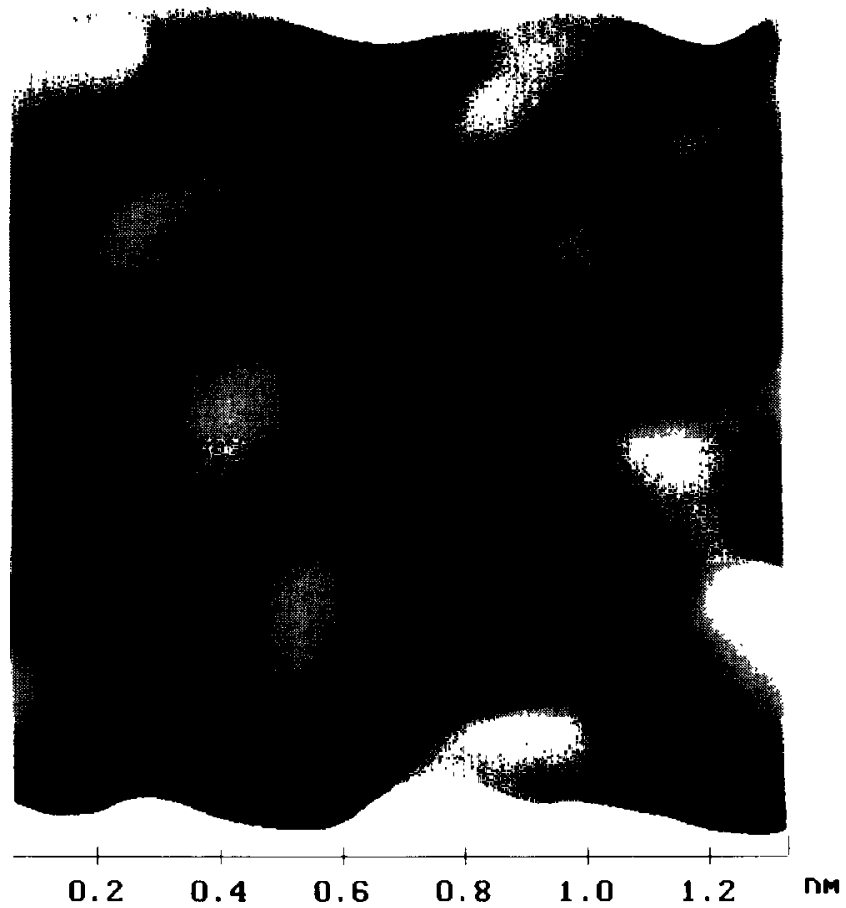

Fig. 5. (a) $7.5 \times 7.5 \mathrm{~nm}^{2} \mathrm{STM}$ image corresponding to the hexagonal ring pattern $\left(q=0.3 \mathrm{mC} \mathrm{cm}^{-2}\right)$. (b) $1.33 \times 1.33 \mathrm{STM} \mathrm{nm} \mathrm{m}^{2}$ image showing the ring structure. (c) $9 \times 9 \mathrm{~nm}^{2}$ STM image showing the bright spot hexagonal pattern. (d) Cross-section showing the spot-spot distance for the array shown in (c). 
C

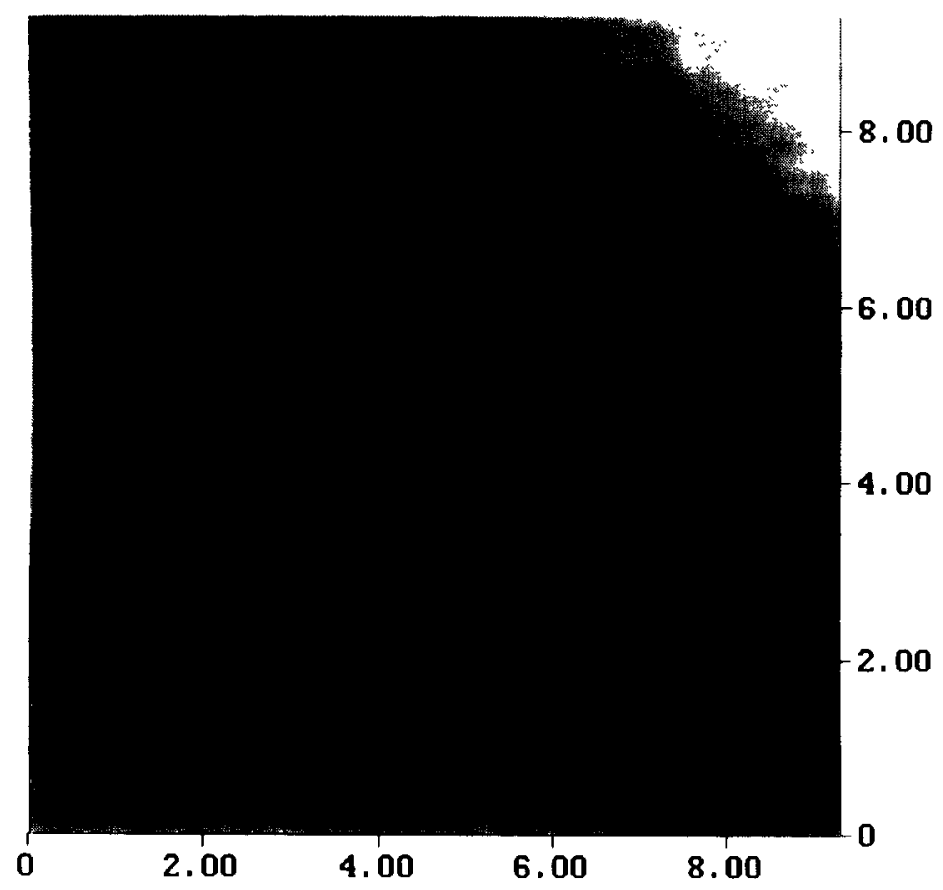

$\mathrm{nm}$

d
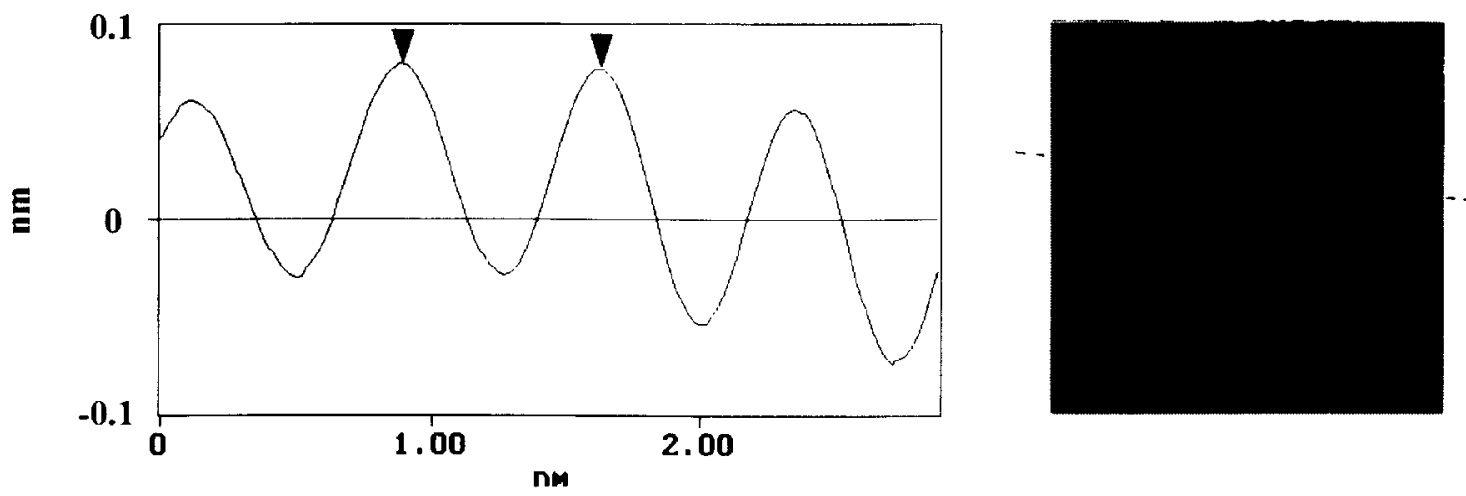

Fig. 5. Continued

ordered domains of bright spots $10 \times 10 \mathrm{~nm}^{2}$ in size. Seemingly, these structures are formed on top of the hexagonal structure as a new pattern (Fig. 6b). These images exhibit two types of ordered structures which are repeatedly imaged. The first type (Fig. $6 \mathrm{c}$ e) is a $0.45 \times 0.6 \mathrm{~nm}^{2}$ domain with a rectangular array involving $d_{\mathrm{z}}=0.1 \mathrm{~nm}$. The second type (Fig. $6 \mathrm{f}-\mathrm{h}$ ) corresponds to a $0.45 \times 0.75 \mathrm{~nm}^{2}$ domain with an array of bright spots with $d_{\mathrm{z}}=0.1 \mathrm{~nm}$, forming $120^{\circ}$ angles between the direction of the spot alignments.

Recent molecular quantum mechanical calculations of polyaniline chain configurations[6] indicate that a minimum energy of the system exists when phenyl rings are alternatively rotated at 14 angles. Accordingly, $d_{\phi t}$, the distance between the centers of adjacent phenyl rings at the ideal molecule, is $d_{\phi \mathrm{t}}=0.50 \mathrm{~nm}$, whereas $d_{\text {cht }}$, the chain-chain distance is $d_{\text {cht }}=0.37 \mathrm{~nm}$. The value $d_{\phi \mathrm{r}}=0.50 \mathrm{~nm}$ is therefore close to the distance $0.45 \mathrm{~nm}$ derived from STM images (Fig. 6c-h). This coincidence would indicate that those bright spots separated by the distance $\mathrm{d}=0.45 \mathrm{~nm}$ could be assigned to phenyl rings in either oligomers or polymer chains. The differences between $d_{\text {eht }}=0.37 \mathrm{~nm}$ and the experimental data $d=0.6 \mathrm{~nm}$ and $d=0.75 \mathrm{~nm}$, could result from either a steric effect produced by anion incorporation into the polymer interchain space, as discussed in reference[6], or less likely, from the influence of 


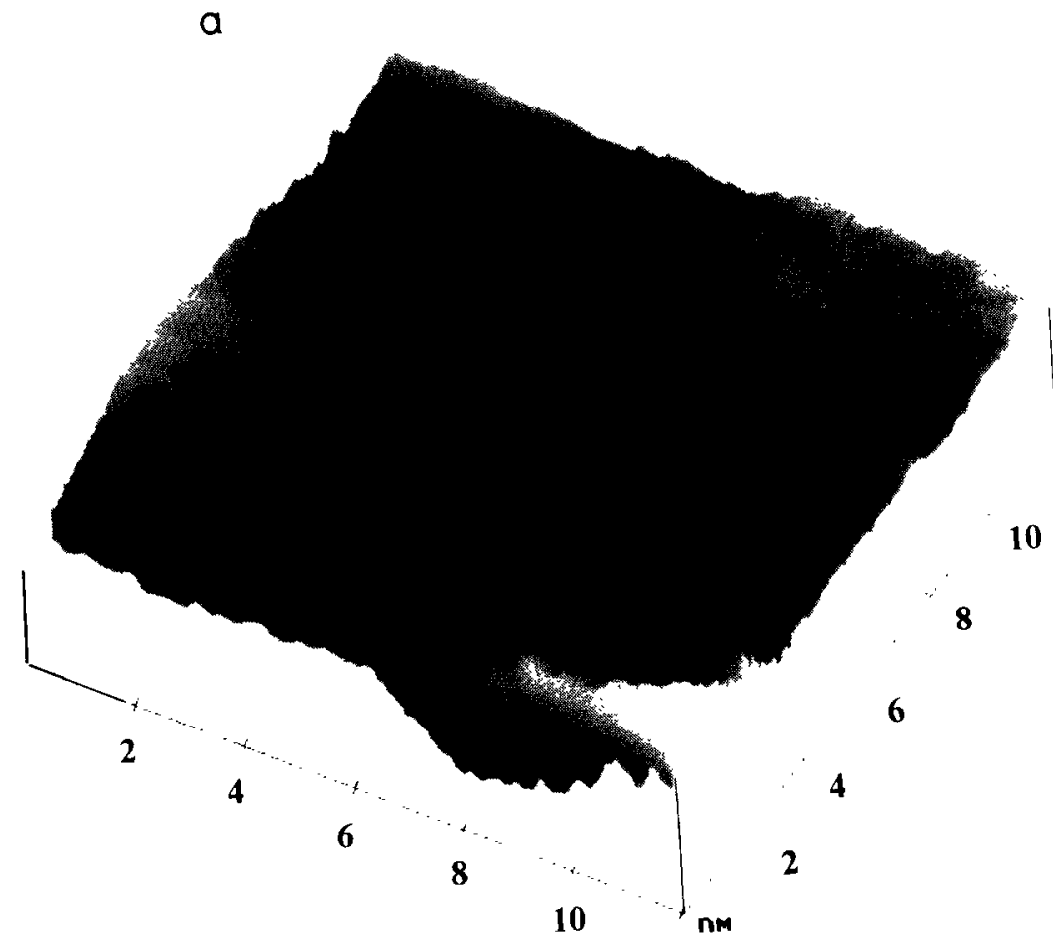

b

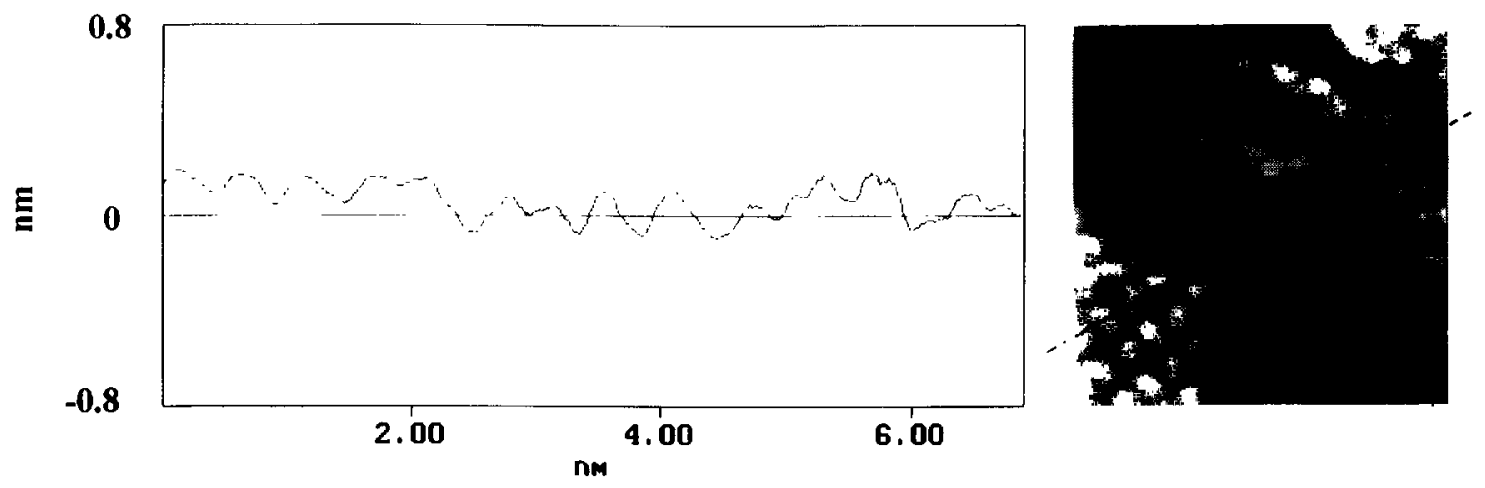

Fig. 6. (a) $12 \times 12 \mathrm{~nm}^{2} \mathrm{STM}$ image showing ordered and disordered domains. $\left(q=0.3 \mathrm{mC} \mathrm{cm}^{-2}\right)$. (b) Cross-section of a zoom corresponding to the image shown in (a). The arrow in the image indicates a hexagonal pattern with $d=0.7 \mathrm{~nm}$. The cross-section indicates that the hexagon (central part) underlies the ordered rectangular array (left hand side) and the fiber-like structures (right-hand side). (c) $5 \times 5 \mathrm{~nm}^{2}$ rectangular array; (d-e) cross-sections following the two directions of the rectangular structure. (f) $6.6 \times 6.6 \mathrm{~nm}^{2}$ STM image showing the $0.5 \times 0.75 \mathrm{~nm}^{2}$ array. $(\mathrm{g}-\mathrm{h})$ cross-section following the two directions of the array shown in (e).

the Au substrate itself on the structure of thin polymer coatings. The presence of one $\mathrm{HSO}_{4}^{-}$anion for each aniline monomer was inferred from radiotracer measurements[18], just at the same potential values at which the polyaniline covered Au electrode was removed from the solution for STM imaging in our experiments. It should be noted that these crystalline deposits coexist with aniline monomer adsorbate domains and strongly disordered polymer fibers.

The above described structures resulting from STM imaging indicate that phenyl rings appear to lie in all cases parallel to the Au surface. On the other hand, STM imaging provides further information concerning some aspects of the early stages of aniline electropolymerization on $\mathrm{Au}$. The lower part of the image shown in Fig. 7 comprises both the above described rectangular arrangements and coated domains where the coating arrangement is incomplete leading to a $0.6 \times 1.0 \mathrm{~nm}^{2}$ rather than a $0.6 \times 0.45 \mathrm{~nm}^{2}$ array. Furthermore, a hexagonal lattice with $d=1.0 \mathrm{~nm}$, although somewhat distorted, can still be observed at the upper part of the image.

The STM imaging of polymer coatings resulting from a more advanced stage of growth 
C

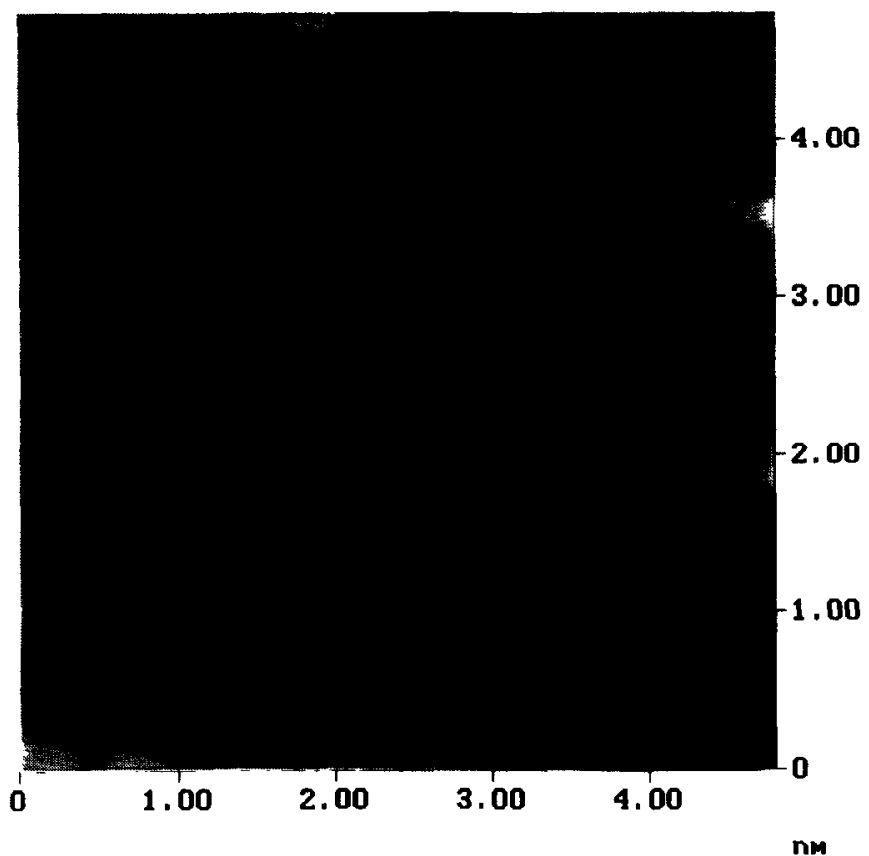

d
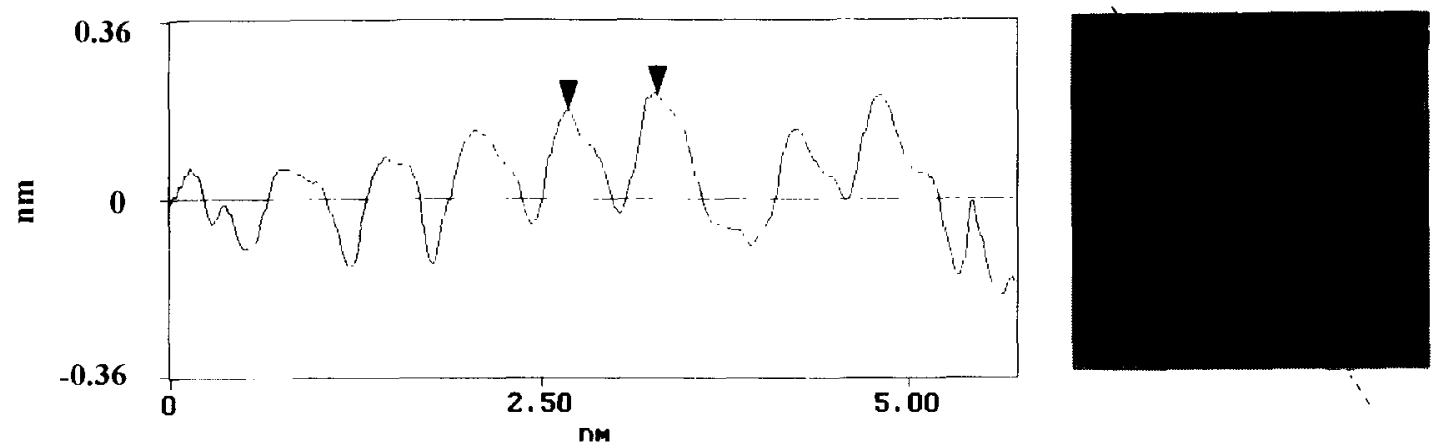

e
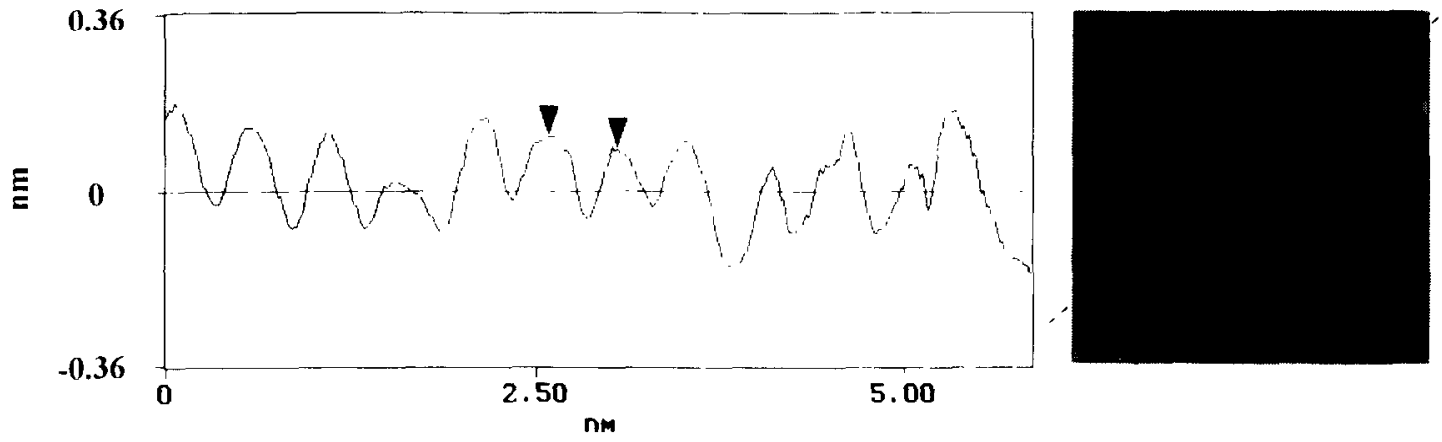

Fig. 6. Continued 

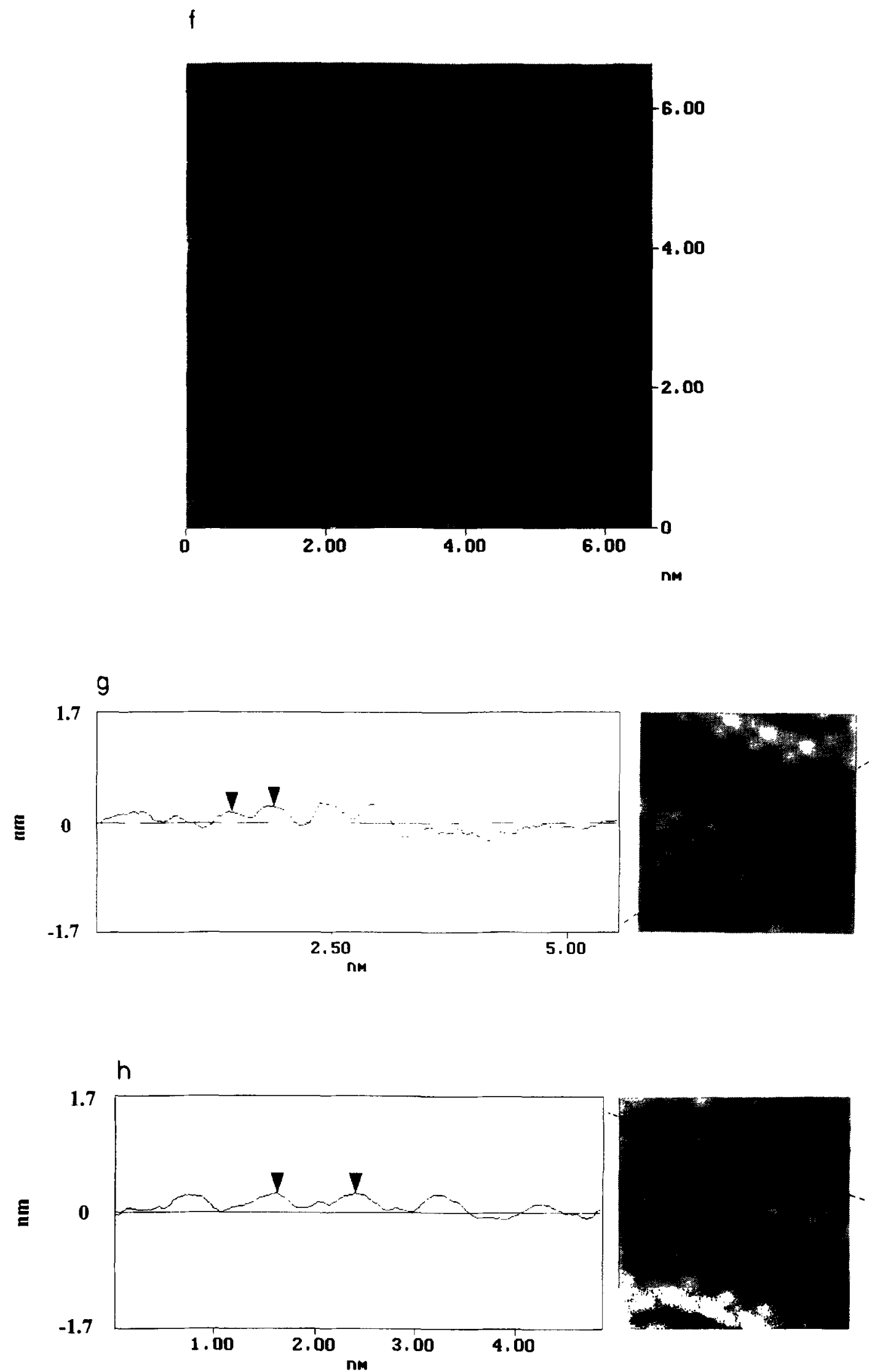

Fig. 6. Cuntinued 


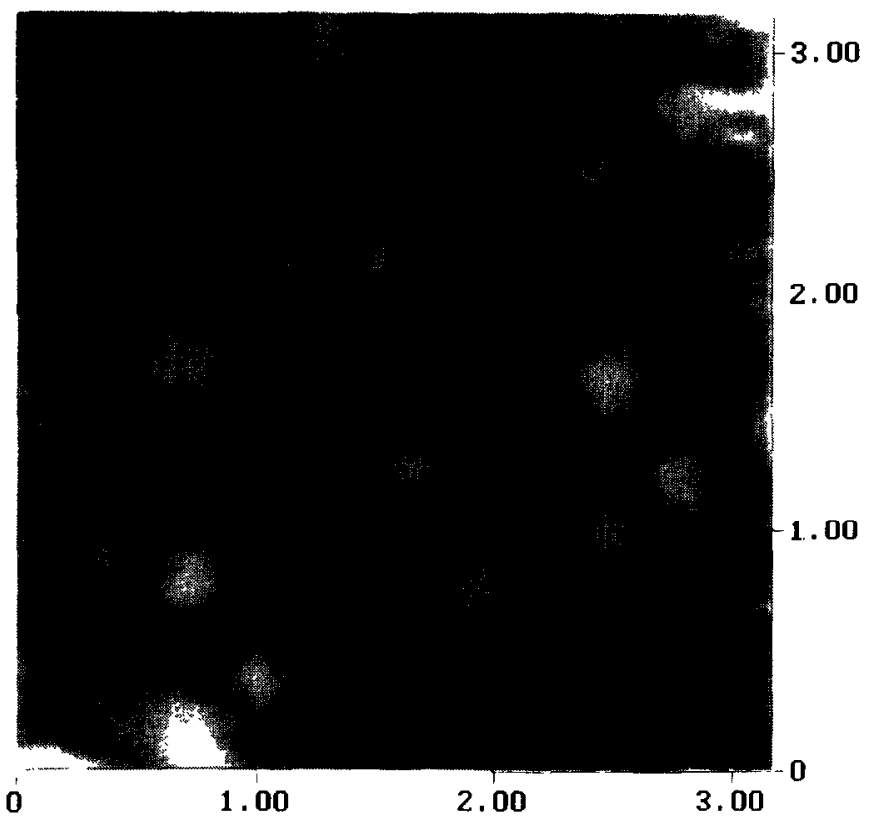

$\mathrm{nm}$

Fig. 7. $3.2 \times 3.2 \mathrm{~nm}^{2}$ STM image showing a hexagonal pattern with $d=1 \mathrm{~nm}$ and the buildup of a $0.45 \times 0.60 \mathrm{~nm}^{2}$ rectangular array $\left(q=0.3 \mathrm{mC} \mathrm{cm}^{-2}\right)$.

$\left(q=1.2 \mathrm{mC} \mathrm{cm}^{-2}\right)$ shows bundles 5 to $20 \mathrm{~nm}$ in size leading to an irregular topography[5]. It should be noted that pores between bundles are in the order of the bundle size. Attempts to obtain resolution of monomers or chains at the bundle surface were unsuccessful. This is not surprising due to the high electron density delocalization in the bundles[19]. In fact, as it has already been discussed[19-20], the high charge delocalization in the bundles is the basis of $3 \mathrm{~d}$ metallic conduction models of polyaniline.

From the precedent data it can be concluded that the polyaniline structure acts as a composite material formed by bundles of close packed polymer chains with interchain separations in the order of $0.60-0.75 \mathrm{~nm}$, and pores $520 \mathrm{~nm}$ in size. Furthermore, anions at bundles should be anchored at positively charged sites of the polymer chains[21], where bundle domains would act as permselective membranes[22]. Otherwise, pores containing anions in solution should be mainly responsible for the ionic conductivity of the polymer, in contrast to the bundle electronic conductivity[23].

The pore structure filled by the electrolyte solution can account for values of diffusivities measurcd for different anions in the polymer structure which result in the order of $10^{-5}-10^{-6} \mathrm{~cm}^{2} \mathrm{~s}^{-1}[23]$.

\subsection{The exclusion of possible artifacts in STM imaging.}

High quality STM images of adsorbed aniline monomer or polyaniline covered domains were systematically obtained in the $20 \mathrm{mV}<V_{\mathrm{t}}<100 \mathrm{mV}$ and $1 \mathrm{nA}<i_{\mathrm{t}}<20 \mathrm{nA}$ range with a gap resistance $R_{\mathrm{g}}$ ranging between $60 \mathrm{M} \Omega$ and $1 \mathrm{M} \Omega$ in the constant current mode. No dependence of the surface structures was observed as $R_{\mathrm{g}}$ is moved from 60 to $1 \mathrm{M} \Omega$.
This fact suggests that tip-sample force interactions are not relevant for adsorbed aniline monomers or polyaniline covered $\mathrm{Au}(111)$, in contrast to the case of organic films deposited on highly oriented pyrolytic graphite (HOPG)[25]. Besides, the imaging of rectangular and hexagonal arrays with distances mismatching the periodicity of the $\mathrm{Au}(111)$ surface allowed us to disregard the presence of Moire patterns, as observed for (HOPG)[26].

It should be noted that extensive etching of $n$ octadecanethiol layers on $\mathrm{Au}(111)$ was reported at $R_{\mathrm{g}} \cong 1 \mathrm{M} \Omega[27]$. In this case, the images change after a few minutes of continuous STM imaging. Conversely, the STM images reported in this work (Figs 4 8) were stable at least for a 300 s continuous STM imaging as shown in Fig. 9 for the fiber-like structure. In all cases, no extensive damage of the polymer surface was obscrved. The difference between the behavior of $n$-octadecanethiol and that of thin polyaniline films is presumably due to the higher conductivity of the polymer film.

\section{CONCLUSIONS}

At potentials in the double layer region more positive than $E_{z}$ for $\mathrm{Au}(111)$ in $0.5 \mathrm{M} \mathrm{H}_{2} \mathrm{SO}_{4}$, aniline monomers are adsorbed parallel to the substrate surface. The electro-oxidation of these monomers takes place at the same potential where aniline polymerization begins.

Hexagonal arrays of adsorbed monomers with $d=0.7 \mathrm{~nm}$ are observed by STM imaging. Monomers are imaged as "spots" or "ring" surface structures, as expected for benzene on transition metals. Other hexagonal arrays of spots with $d=0.5$ and $d=1.0 \mathrm{~nm}$ were also observed. 

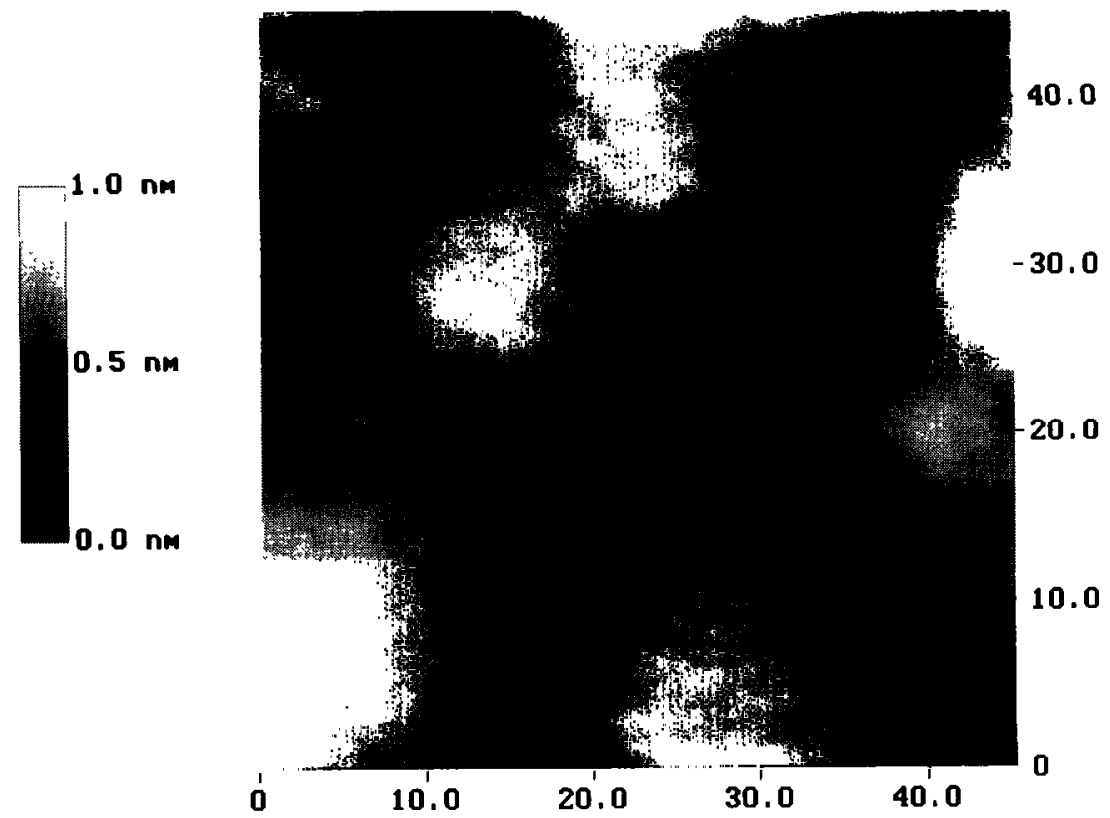

$n M$

Fig. $8.45 \times 45 \mathrm{~nm}^{2}$ STM image of a thick polymer film $\left(q=1.2 \mathrm{mC} \mathrm{cm}^{-2}\right)$ showing the typical bundle structure.

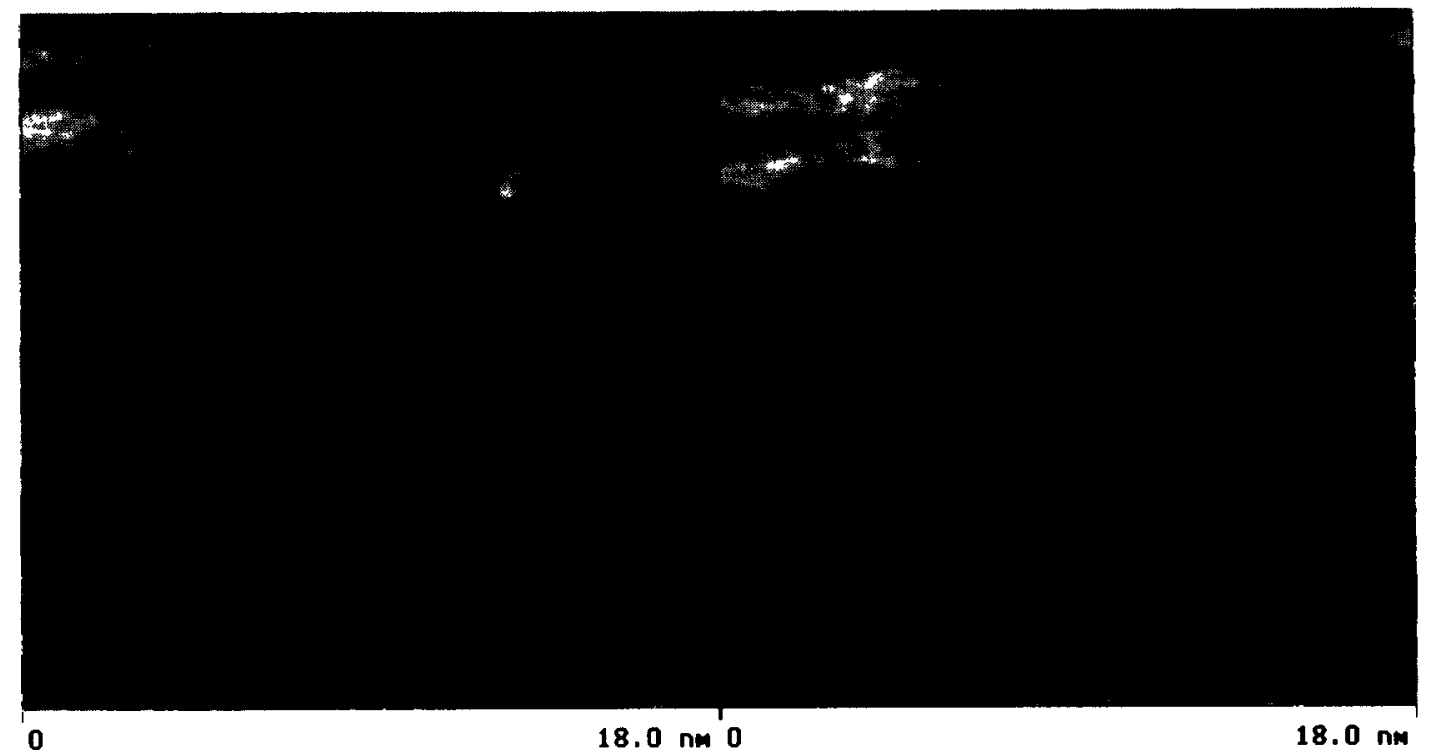

Fig. 9. (a) $18 \times 18 \mathrm{~nm}^{2} \mathrm{STM}$ image of the fiber-like structure in the polymer film $\left(q=0.3 \mathrm{mC} \mathrm{cm}^{-2}\right)$. (b) STM image of the same domain after a continuous 300 s STM imaging. No appreciable damage of the surface layer structure is observed.

Ordered arrays $0.45 \times 0.6 \mathrm{~nm}^{2} \quad$ and $0.75 \times 0.45 \mathrm{~nm}^{2}$ in size and $d_{\mathrm{z}}=0.1 \mathrm{~nm}$ can be assigned to either oligomers or polymer chains. Ordered domains coexist with highly disordered ones where monomers are located at random.

Polymer chains agglomerate yielding fibers $2 \mathrm{~nm}$ in average thickness. Advanced electropolymerization stages lead to the formation of polymer bundles and pores yielding a coating with an irregular topography.

Acknowledgement-This research project was supported by the Consejo Nacional de Investigaciones Cientificas y Tècnicas (CONICET), Argentina, within the frame of the cooperation agreement between CONICET and Consejo Superior de Investigaciones Científicas (CSIC), Spain. 


\section{REFERENCES}

1. G. P. Evans, in "Advances in Electrochemical Science" and Engineering", (Edited by H. Gerischer and C. W. Tobias), Vol. 1, VCH Weinheim (1990).

2. E. M. Geniès, M. Lapkowski and C. Tsintavis, New J. Chem. 12, 181 (1988).

3. J. Lakkari, PhD Thesis, University of Turku, Finland (1993).

4. T. L. Porter, Surf. Science 293, 81 (1993).

5. P. Ocón, P. Herrasti, J. M. Vara, L. Vázquez, R. C. Salvarezza and A. J. Arvia, J. Phys. Chem. 98, 2418 (1994).

6. C. Bai, C. F. Zhu, P. C. Zhang. T. Yu and F. S. Wang. J. Vac. Sci. Technol. B 12, 1927 (1994).

7. C. Bai, C. F. Zhu, G. Huang, J. Tang, M. Wan and R. Chen. Ultramicroscopy 42-44, 1079 (1992).

8. T. R. Albrecht, H. A. Mizes, J. Nogami, Sang-il Park and C. F. Quate, Appl. Phys. Lett. 52, 362 (1988)

9. J. L. Zubimendi, M. E. Vela, R. C. Salvarezza, L. Vázquez, J. M. Vara and A. J. Arvia, Phys. Rev. E 50, 1367 (1994).

10. K. Bode, V. Tsakova and J. W. Schultze, Electrochim. Acta 12, 2255 (1992).

11. P. Zelanay, L. M. Rice-Jackson and A. Wieckowski, $J$. Electroanal. Chem. 283, $389(1990)$

12. R. Albalat, J. Claret, J. M. Feliu and J. Clavilier, $J$. Electroanal. Chem. 288, 277 (1990).

13. R. J. Behm in Scanning Tunneling Microscopy and Related Methods, (Edited by R. J. Behm. N. Garcia and H. Rohrer), Kluwer Academic Publisher. Dordrecht, NATO ASI Series E, vol. 184, 1989 p. 173, and references therein.
14. J. Lecoeur, J. P. Bellier and C. Koehler, J. Electroanal. Chem. 337, 197 (1992).

15. P. Sautet and M. L. Bocquet Surf. Sci. 304, L445 1994.

16. "Scanning Tunneling Microscopy I" (Edited by H. J. Güntherodt and R. Wiesendanger), Springer-Verlag, Berlin (1994).

17. C. Nguyen Van Huong, J. Electroanal. Chem. 264, 247 (1989).

18. V. E. Kazarinov, V. N. Andreev, M. A. Spytsin and A. V. Shlepakov, Electrochim. Acta 35, 899 (1990).

19. Z. H. Wang, C. Li, E. M. Scherr, A. G. MacDiarmid and A. J. Epstein, Phys. Rev. Lett. 66, 1745 (1991).

20. I. Z. Wang, C. H. Hsu, J. P. Pouget and E. J. Epstein, Phys. Rev. B 50, 16811 (1994).

21. M. A. Vorotyntsev, International Workshop on the Electrochemistry of Electroactive Polymers, 8-12 April, Moscow (1995).

22. P. G. Pickup, International Workshop on the Electrochemistry of Electroactive Polymers, 812 April. Moscow (1995).

23. P. G. Pickup, J. Chem. Soc. Faraday Trans. 86, 3631 (1990).

24. C. Deslouis, T. El Moustafid, M. M. Musiani and B. Tribollet, International Workshop on the Electrochemistry of Electroactive Polymers: 8-12 April, Moscow (1995).

25. A. Wawkuschewski, H. J. Cantow and S. N. Magonov, Lanymuir 9, 2778 (1993).

26. M. Whangbo, W. Liang, J. Ren, S. N. Magonov and A. Wawkuschewski, J. phys. Chem. 98, 7606 (1994).

27. Y. Kim and A. J. Bard, Langmuir 8, 1096 (1992). 